\title{
A STUDY ON VISUAL ACUITY OUTCOME ANALYSIS OF PATIENTS WITH APODIZED DIFFRACTIVE MULTIFOCAL IOL IN TERTIARY CARE CENTRE
}

\author{
Ramesh Rajasekaran1, Ashok Balagopal2, Meenakumari ${ }^{3}$, Prasanna Venkatesh Ramesh ${ }^{4}$, Kalai Mohan ${ }^{5}$ \\ ${ }^{1}$ Chairman, Department of Ophthalmology, Mahathma Eye Hospital, Tiruchirappalli, Tamilnadu, India. \\ ${ }^{2}$ General Ophthalmologist, Department of Ophthalmology, Mahathma Eye Hospital, Tiruchirappalli, Tamilnadu, India. \\ ${ }_{3}^{3}$ Medical Director, Department of Ophthalmology, Mahathma Eye Hospital, Tiruchirappalli, Tamilnadu, India. \\ ${ }^{4}$ Fellow-Medical Officer, Dr. Sathyan Hospital, Coimbatore, Tamilnadu, India. \\ ${ }_{5}^{5}$ General Ophthalmologist, Department of Ophthalmology, Mahathma Eye Hospital, Tiruchirappalli, Tamilnadu, India.
}

\section{ABSTRACT}

\section{BACKGROUND}

The success of performing modern cataract surgery, where the technique and technology that goes hand in hand has increased, the expectation of patients towards spectacle independence has increased. In the earlier years, multifocal IOLs were used extensively. But the outcome was surprisingly suboptimal in the form of post-op refractive surprises, spectacle dependency, reduced reading speed, reduced level of contrast sensitivity and most alarmingly the photic phenomena (halos, glare, starburst etc.). Then started the evolution of various types of multifocal IOLs, i.e. Refractive IOLs, diffractive IOLs, diffractive-refractive IOLs, accommodative IOLs, IOLs with extended depth of focus etc.

Aim- To analyse the visual acuity outcome of apodized diffractive multifocal IOL of patients and their satisfaction level. Single surgeon retrospectively enrolled patients for bilateral implantation of apodized multifocal IOL.

\section{MATERIALS AND METHODS}

Casual acuity assessment in the post-operative period include distant vision and near vision. Patient's satisfaction was surveyed at the end of three months and one year after cataract surgery by means of a question naire. Two hundred and fifty patients of both sexes of age group 40 to 90 were enrolled. Their distant vision and near vision were assessed at one month, three months and one year post-operatively using Snellen visual acuity chart and document. The mean patient satisfaction in the form of reading speed, spectacle independence, to perform their hobbies etc. were assessed using a questionnaire called Response Rating Scale. Patients were highly satisfied with their vision and spectacle independence.

\section{RESULTS}

35.6 percent of patients had $6 / 6$ nil glasses. 38.8 percentage of them had $6 / 9$ vision and 2.8 percentage were unhappy patients. None of them needed their multifocal IOL explanted.

\section{CONCLUSION}

In summary, though most patients achieve spectacle independence with MF IOL, some have unsatisfactory visual outcome. If from day 1 to till 1-month post-operative period, patient is not happy with the visual outcome or experience, a very disturbing photic phenomenon IOL explanation is suggested.

\section{KEY WORDS}

Visual Acuity, Outcome Analysis, Apodized Diffractive, Multifocal IOL, Patient Satisfaction, Response Rating Scale, Unhappy Patients.

HOW TO CITE THIS ARTICLE: Rajasekaran R, Balagopal A, Meenakumari, et al. A study on visual acuity outcome analysis of patients with apodized diffractive multifocal IOL in tertiary care centre. J. Evolution Med. Dent. Sci. 2018;7(47):5113-5117, DOI: $10.14260 /$ jemds/2018/1136

\section{BACKGROUND}

The success of performing modern cataract surgery, where the technique and technology that goes hand in hand, has increased the expectation of patients towards spectacle independence. Initially, in the earlier years the multifocal IOL were used extensively.

'Financial or Other Competing Interest': None.

Submission 01-11-2018, Peer Review 13-11-2018,

Acceptance 15-11-2018, Published 19-11-2018.

Corresponding Author:

Dr. Ramesh Rajasekaran,

Chairman,

Mahathma Eye Hospital,

No. 6 Seshapuram,

Tiruchirappalli,

Tamilnadu, India

E-mail: meh.drramesh@gmail.com

DOI: $10.14260 /$ jemds $/ 2018 / 1136$

\section{(c) $(1)(9)$}

But the outcome was surprisingly suboptimal in the form of post-op refractive surprises, spectacle dependency, reduced reading speed, reduced level of contrast sensitivity and most alarmingly the photic phenomena (Halos, Glare, Starburst etc.). Then started the evolution of various types of multifocal IOLs, i.e. Refractive IOLs, diffractive IOLs, diffractive- refractive IOLs, accommodative IOLs, IOLs with extended depth of focus etc. Satisfactory was the multifocal IOL with $+4 \mathrm{D}$ add at the IOL plane, yielding +3.2D add at the spectacle plan which had apodized technology, asphericity and diffractive which gave spectacle independence in $70 \%$ of the patients.1,2,3,4,5 Then evolved the apodized multifocal IOL with $+3 \mathrm{D}$ add at the spectacle plane yielding spectacle independence in $88 \%$ of patients. ${ }^{6}+3 \mathrm{D}$ add multifocal IOL has 9 diffractive steps. This aspheric IOL model has a $6.0 \mathrm{~mm}$ optic with a central zone of $3.6 \mathrm{~mm}$ apodization and outer refractive zone. The apodization technology means gradual decrease in the height in steps from center to periphery. This 
claims to reduce the photic phenomenon and also results in smooth transition in distant vision from near as the pupil enlarges. ${ }^{7}$ The aspheric design constitute of negative spherical aberration to compensate for positive corneal spherical aberrations. The $+3 \mathrm{D}$ add produced desired better intermediate vision. The near point was designed to improve intermediate vision. Careful patient selection, excellent history taking to assess the patient personality profile, subjecting every patient to detailed clinical evaluations using necessary diagnostic modalities, selecting appropriate IOL formulas and validating the IOL power could certainly increase the number of patients with spectacle independence and the happy patient profile also increases to be more than $90 \%$.

Hence, the present study was designed in a single centre to evaluate the visual acuity and patient satisfaction levels after bilateral implantation of $+3 \mathrm{D}$ aspheric apodized multifocal IOL.

\section{MATERIALS AND METHODS}

This is a retrospective cohort study. This study involves patients ranging from 40 years of age to 80 years of age of both sexes. The sample size was 250 patients who underwent bilateral multifocal IOL with aspheric design using apodized technology with $+3 \mathrm{D}$ add. Very careful selection of the patients were done. A detailed questionnaire was given to the patients including the nature of work and type of hobbies, ex: cooking, knitting bags, tailoring, swimming, walking, playing video games, playing golf, painting, gardening, watching TV, the time spent on social media etc. was interacted with the patients in a detailed fashion. The reading desire of the patient or his necessity to read is assessed. The type of reading material and the duration of reading hours, the time duration spent with spectacles for near vision task were analysed. Their necessity/ desire to drive two-wheeler or four wheelers was also analysed. The duration of driving and whether it is day time or night time driving were studied.

The personality profile of the patients was understood by a prolonged chair time. The prior information was given to the patients about the photic phenomenon and the possibility of minimal dependency of glasses and their expressions observed. All patients with type A personality having over expectation were deleted for MF IOL implantations. Patients with more than $0.75 \mathrm{D}$ to $1.0 \mathrm{D}$ are excluded for MF IOL. Patients with corneal degenerative changes and corneal dystrophies, any form of pupillary abnormalities, any fundus, macular or optic nerve head pathologies were not offered MF technology. Patients who had undergone retinal surgeries, monofocal IOL in one eye were not offered MF IOL. Patients who had undergone surgeries for strabismus or with history of amblyopia were also not taken up.

All the patients were subjected to diagnostic evaluation tool like OCT for any subtle macular/ foveal pathologies like IS/ OL junction disruption wherever visual acuity assessment cannot be done Retina Acuity Metre was used to predict the visual outcome. Aberrometry was performed in all the patients willing for MF IOL. Patients having higher order aberrations - coma more than 33 were not taken up for MF IOL. Angle kappa was evaluated using a synoptophore or optical biometry. Patients with more than $5^{\circ}$ angle kappa were not taken up for MF IOL surgery.

Visual acuity outcome analysis was done using Snellen's visual acuity chart- One month, three months and one-year post-op and documented. Patient's satisfaction in one month, three months and 1-year post-operative period were assessed using response rating scale. Surgical technique aiming precision in post-operative visual acuity. All the patients were operated with limbal corneal $2.2 \mathrm{~mm}$ main incision and $1 \mathrm{~mm}$ sideports. The incision side was temporarily located unless the steep meridian was found elsewhere, especially when the patient selected had an astigmatism of $0.75 \mathrm{D}$ or $1.0 \mathrm{D}$. Patients with all grades of cataract were involved in the study. In all the patients, a rhexis marker of $5.5 \mathrm{~mm}$ diameter was used to impress upon the clear cornea. Continuous curvilinear capsulorhexis of 5 $\mathrm{mm}$ was performed with the rhexis marker of $5.5 \mathrm{~mm}$ as a guiding tool. In most of the cases, this was achieved with the exception of few cataracts like mature and hypermature cataracts. This $5 \mathrm{~mm}$ rhexis ensured $1 \mathrm{~mm}$ overlap of the 6 $\mathrm{mm}$ optic. All the cataracts were emulsified using gravitybased fluid system and OZil technology using Kelman MiniFlared $45^{\circ}$ angled phaco needle.

\section{Statistical Analysis}

The data was analysed using SPSS (version 17.0) software. The frequency (no. of respondents) and percentage (\%) of respondents selected for the study were analysed through the software.

\begin{tabular}{|c|c|}
\hline Questionnaire Section & Response Rating Scale \\
\hline \multicolumn{2}{|l|}{ Visual Disturbance Items } \\
\hline $\begin{array}{c}\text { How much difficulty do you have with each of the following? } \\
\text { Glare/ Flare (trouble seeing street signs due to bright light or oncoming } \\
\text { headlights) } \\
\text { Night vision } \\
\text { Colour perception (trouble recognising specific colours) } \\
\text { stairs) } \\
\text { Depth perception (trouble lining things up pouring liquids or going down } \\
\text { Halos (rings around lights) } \\
\text { Distorted near vision (straight lines look crooked close-up) } \\
\text { Distorted far vision (straight lines look crooked at distance) } \\
\text { Blurred near vision } \\
\text { Blurred far vision } \\
\text { Double vision }\end{array}$ & $\begin{array}{c}0=\text { no difficulty } \\
1=\text { minimal difficulty } \\
2 \text { or } 3=\text { moderate difficulty } \\
4 \text { or } 5=\text { severe difficulty }\end{array}$ \\
\hline
\end{tabular}


How much difficulty do you have with each activity due to your vision?

(without glasses or contact lenses)

Watching TV or movies

Playing or working outside

Caring for/ playing with children

Reading the time on an alarm clock

Performing your job/ hobbies

Participating in sports/ recreation

Participating in social events

Reading and near work/ activities Driving at night

Driving when it is raining

Using a computer

Cooking

Shopping

Using a cell phone

Shaving or putting on makeup

\begin{tabular}{|c|c|}
\hline \multicolumn{2}{|c|}{ Spectacle Use } \\
\hline $\begin{array}{c}\text { How often do you wear glasses or contacts? } \\
\text { How often do you wear glasses or contacts........ } \\
\text {.....for distance vision } \\
\text {.....for intermediate vision? } \\
\text {......for near vision? }\end{array}$ & $\begin{array}{c}\text { Always, sometimes, never } \\
\text { Never, rarely, occasionally, } \\
\text { often, always }\end{array}$ \\
\hline \multicolumn{2}{|c|}{ Satisfaction } \\
\hline On a scale of 1 to 10, how satisfied are you with your vision? & $1=$ least, $0=$ most \\
\hline \multicolumn{2}{|c|}{ Response Rating Scale } \\
\hline
\end{tabular}

\section{RESULTS}

In the present investigation, a sample of 250 individuals of both male and female were taken. Among 250 patients, 123 were males and 127 were females, which revealed that both males and females had equal desire and opportunities for advanced technology IOL, namely Multifocal IOL. The results were tabulated in Table 1.

The different age group of patients from 30 to 90 years old were selected for the present study. This includes both the gender to study the visual acuity outcome in multifocal IOLs. Of the different age group of patients studied, the highly productive age of less than 40 years were heavily committed professionally and economically. This age group is highly committed to near vision task and to outdoor activities, which involved driving either during the day time or night time. Hence, those who opted/ selected for multifocal technology were minimum $(0.8 \%)$. Followed by the age group of more than 80 years of patients who were least $(2.4 \%)$ motivated for premium IOL technology. The age of 60 to 69 years old patients was observed as the most motivated age group for spectacle independence for distance, near and intermediate, in which $38 \%$ was noticed followed by the age group of 50 to 59 years old patients (32\%) (Table 2). These results indicate that the middle-aged patients had more expectation towards spectacle independence and were willing to tolerate minimal visual disturbances encountered after multifocal IOL implantation as a trade-off for spectacle independence.

The frequency distribution of the respondents with uncorrected visual acuity during one week and one month post-op were documented. The results revealed that $38.8 \%$ of the patients had uncorrected visual acuity after 1-week treatment for distant vision acuity at the level of $6 / 9$, followed with $35.6 \%$ of patients had normalisation upto $6 / 6$ of vision after 1 -week treatment, $18 \%$ had corrected vision upto $6 / 18$ level and to the least $0.4 \%$ of patients had treatment upto $6 / 36$ level. The results were depicted in
Table 3. The results in Table 4 showed out of 250 patients, $35.6 \%$ of them had unaided vision of $6 / 6.38 .8 \%$ of them improved from $6 / 9$ to $6 / 6$ with minimal correction of $0.25 \mathrm{D}$ to $0.50 \mathrm{D}$. $18 \%$ of them improved from $6 / 12$ to $6 / 6$ with correction of less than $0.75 \mathrm{D}$. $1.6 \%$ of the patients who did not improve were diagnosed with PCO. One patient who had 6/36 nig, nip had diabetic macular oedema, which was missed preoperatively. Frequency distribution of the respondents with near vision acuity was given in Table 5 and the results showed that after 1-week treatment for near vision acuity, out of 250 patients $94.4 \%$ had normalisation of vision upto level of N6 and followed by $2.4 \%$ were treated upto level of N8 and to the least $0.4 \%$ were treated upto N24 level. Based on the present study, it is inferred that out of 250 patients $243(97.2 \%)$ were satisfied with the vision after multifocal IOL implantation, while 7 (2.8) respondents were not satisfied with the visual outcome because four of them had PCO, one had diabetic maculopathy and the other two had photic phenomena (Table 6).

In the postop, it is inferred that $93.2 \%$ of 250 patients had good reading ability and speed after the treatment with multifocal IOL implantation, but $6.8 \%$ (Table 7) of them did not have good vision for reading. They were advised to read under good illumination.

The frequency distribution of patients based on their IOL power of the eye, for which they had treatment were analysed and tabulated in Table 8 . Among 250 patients $60.4 \%$ had 21 - 25D of IOL power, 30.8\% had 16 - 20D power and showed low myopes, $5.6 \%$ had 11 - 15D power and were high myopes and only $3.2 \%$ had more than 25D power and small eyes. At the end of one month, the questionnaire was given to patient for assessing the satisfaction level on visual performance on day-to-day life. The results showed that under the Response Rating Scale, there was no difficulty or minimum difficulty with 25 - 27 items. The patients related to 
the items pertaining to driving showed no difficulty or minimal-to-moderate difficulty.

\begin{tabular}{|c|c|c|}
\hline Gender & Frequency & Percent (\%) \\
\hline Male & 123 & 49.2 \\
\hline Female & 127 & 50.8 \\
\hline Total & 250 & 100.0 \\
\hline \multicolumn{3}{|c|}{$\begin{array}{l}\text { Table 1. Frequency distribution of the Respondents based } \\
\text { on their Gender }\end{array}$} \\
\hline
\end{tabular}

\begin{tabular}{|c|c|c|}
\hline Age & Frequency & Percent (\%) \\
\hline$<40$ yrs. & 2 & 0.8 \\
\hline 40-49 yrs. & 41 & 16.4 \\
\hline 50-59 yrs. & 80 & 32.0 \\
\hline 60-69 yrs. & 96 & 38.4 \\
\hline 70-79 yrs. & 25 & 10.0 \\
\hline$>80$ yrs. & 6 & 2.4 \\
\hline Total & 250 & 100.0 \\
\hline \multicolumn{3}{|c|}{$\begin{array}{l}\text { Table 2. Frequency distribution of the Respondents based } \\
\text { on their Age }\end{array}$} \\
\hline
\end{tabular}

\begin{tabular}{|c|c|c|}
\hline UCVA (1st Postop) & Frequency & Percent \\
\hline $6 / 6$ & 89 & 35.6 \\
\hline $6 / 9$ & 97 & 38.8 \\
\hline $6 / 12$ & 45 & 18.0 \\
\hline $6 / 18$ & 14 & 5.6 \\
\hline $6 / 24$ & 4 & 1.6 \\
\hline $6 / 36$ & 1 & 0.4 \\
\hline Total & $\mathbf{2 5 0}$ & $\mathbf{1 0 0 . 0}$ \\
\hline
\end{tabular}

Table 3. Frequency distribution of the Respondents with Uncorrected Visual

Acuity during 1 week and 1 month Postop

\begin{tabular}{|c|c|c|}
\hline BCVA (1st Post OP) & Frequency & Percent \\
\hline $6 / 6$ & 89 & 35.6 \\
\hline $6 / 9-6 / 6$ & 97 & 38.8 \\
\hline $6 / 12-6 / 6$ & 45 & 18.0 \\
\hline $6 / 18-6 / 6$ & 14 & 5.6 \\
\hline $6 / 24-$ nig, nip & 4 & 1.6 \\
\hline $6 / 36$ & 1 & 0.4 \\
\hline Total & $\mathbf{2 5 0}$ & $\mathbf{1 0 0 . 0}$ \\
\hline
\end{tabular}

Table 4. Frequency distribution of the Respondents with Best Corrected Visual Acuity during 1 week and 1 month Postop

\begin{tabular}{|c|c|c|}
\hline Near Vision (1 & \\
\hline Nt Postop) & Frequency & Percent \\
\hline N8 & 236 & 94.4 \\
\hline N10 & 6 & 2.4 \\
\hline N12 & 4 & 1.6 \\
\hline N24 & 3 & 1.2 \\
\hline Total & 1 & 0.4 \\
\hline
\end{tabular}

Table 5. Frequency distribution of the Respondents with Near Vision Acuity during 1 week and 1 month Postop

\begin{tabular}{|c|c|c|}
\hline Patient Satisfaction & Frequency & Percent \\
\hline No & 7 & 2.8 \\
\hline Yes & 243 & 97.2 \\
\hline Total & $\mathbf{2 5 0}$ & $\mathbf{1 0 0 . 0}$ \\
\hline
\end{tabular}

Table 6. Frequency distribution of the Respondents based on their Satisfaction about the Spectacle Independence

\begin{tabular}{|c|c|c|}
\hline Reading Ability & Frequency & Percent \\
\hline Good & 233 & 93.2 \\
\hline Not Good & 17 & 6.8 \\
\hline Total & $\mathbf{2 5 0}$ & $\mathbf{1 0 0 . 0}$ \\
\hline
\end{tabular}

Table 7. Frequency distribution of the Respondent's Reading Ability after the Vision Treatment

\begin{tabular}{|c|c|c|}
\hline IOL Power & Frequency & Percent \\
\hline $11-15 \mathrm{D}$ & 14 & 5.6 \\
\hline $16-20 \mathrm{D}$ & 77 & 30.8 \\
\hline $21-25 \mathrm{D}$ & 151 & 60.4 \\
\hline$>25 \mathrm{D}$ & 8 & 3.2 \\
\hline Total & $\mathbf{2 5 0}$ & $\mathbf{1 0 0 . 0}$ \\
\hline
\end{tabular}

Table 8. Frequency distribution of the Respondents based on their IOL Power after the Treatment for Vision

\section{DISCUSSION}

\section{Post-0p Assessment}

Post-op slit lamp examination, visual acuity assessment refraction was alone in 1 week/ 1-month postoperative period. No significant difference in the visual acuity was noted at 3 months, 1-year postoperative period. Visual acuity one-month post-op was taken for the study purpose. Fundus evaluation was done at 1 month postoperative, then onwards every visit. 4 patients were noted to have PCO. One patient had fundus pathology, for whom there was moderate visual loss.

The UCVA and BCVA for both near and distance in the patients after implantation of bilateral aspheric apodized MFIOL +3 D add was assessed one week and one-month postop.

From the present study it was observed that near, intermediate and distant vision was better in $97.3 \%$ of patients using $+3 \mathrm{D}$ add. In contrast to the present study, $75 \%$ reported that the $+4 \mathrm{D}$ add gives better visual acuity for distance intermediate using the same technology.

At the end of one month, the questionnaire finds under the Response Rating Scale there was no difficulty or minimum difficulty with 25 - 27 items. The patients related to the items pertaining to driving as no difficulty or minimal-tomoderate difficulty. In the present study, the high expectation of spectacle independence was a noticeable outcome and spectacle independence was attributed to the apodized diffractive optics, which could be the reason for the reduction in the photic phenomenon. Another equally important reason is strictly adhering to the patient selection criteria. Apart from the optic design, visual disturbances could be resulting from ocular straylight due to PCO. In our study 4 patients who developed significant PCO, YAG capsulotomy was done following which patients had considerable relief from photic experience and visual acuity also improved. After successful bilateral implantation of the $+3 \mathrm{D}$ add aspheric apodized diffractive IOL implantations, $97.2 \%$ of our patients had complete spectacle independence for vision for various distance namely near, intermediate and infinity which is more than the FDA clinical trials in which they find $88 \%$ of positive results.

High level of spectacle independence, minimal or no visual disturbances in the form of photic phenomenon, absence of PCO are all co-related with patient's satisfaction. Unhappy patients have been attributed to those who do not achieve visual goals, have compromises in the quality and sharpness of vision or with newer aberrations. ${ }^{8-17}$

In a study by Chiasmet, $21.3 \%$ of patients with apodized IOL had moderate glare as compared to $7.5 \%$ of patients with Monofocal IOLs. Pieh et al claimed that halos can appear under high contrast conditions. ${ }^{18}$ Visual complaints in the postoperative period has to be managed after a systematic 
approach. In patients who had residual astigmatism of preexisting 0.75 to $1.0 \mathrm{D}$ cylindrical power or a new spherical error, they can be counselled and prescribed for spectacle correction. Patients who are not able to read under dim lighting conditions were advised to read under bright illuminations or natural lighting.

\section{CONCLUSION}

Minimal visual disturbances involved in the multifocal IOL in the form of photic phenomenon, blurred vision etc., are considered as a trade-off for spectacle independence. Understanding the technology in the multifocal IOL being used, strictly adhering to the patient selection criteria, sticking onto the relative and absolute contraindications, subjecting the patients to all the necessary preoperative assessment tools, helps in reducing the number of unhappy patients in the post-op period. Rejecting the one-eyed patients, patients with higher order aberrations more than 33 $\mu \mathrm{m}$, angle kappa more than $5^{\circ}$ gives good number of happy patients.

In summary, though most patients achieve spectacle independence with MF IOL, some have unsatisfactory visual outcome. If from day 1 to till 1-month postoperative period patient is not happy with the visual outcome or experience very disturbing photic phenomenon, IOL explanation is suggested.

\section{REFERENCES}

[1] Kohnen T, Allen D, Boureau C, et al. European multicenter study of the AcrySof ReSTOR apodized diffractive intraocular lens. Ophthalmology 2006;113(4):578-84.e1.

[2] Alfonso JF, Ferna'ndez-Vega L, Baamonde MB, et al. Prospective visual evaluation of apodized diffractive intraocular lenses. J Cataract Refract Surg 2007;33(7):1235-43.

[3] Chang DF. Prospective functional and clinical comparison of bilateral ReZoom and ReSTOR intraocular lenses in patients 70 years or younger. J Cataract Refract Surg 2008;34(6):934-41.

[4] Chiam PJT, Chan JH, Aggarwal RK, et al. ReSTOR intraocular lens implantation in cataract surgery: quality of vision. J Cataract Refract Surg 2006;32(9):1459-63, erratam 1987.

[5] Chiam PJT, Chan JH, Haider SI, et al. Functional vision with bilateral ReZoom and Re-STOR intraocular lenses 6 months after cataract surgery. J Cataract Refract Surg 2007;33(12):2057-61.

[6] Kohnen T, Nuijts R, Levy P, et al. Visual function after bilateral implantation of apodized diffractive aspheric multifocal intraocular lenses with a $+3.0 \mathrm{D}$ addition. J Cataract Refract Surg 2009;35(12):2062-9.
[7] Davison JA, Simpson MJ. History and development of the apodized diffractive intraocular lens. J Cataract Refract Surg 2006;32(5):849-58.

[8] Lee ES, Lee SY, Jeong SY, et al. Effect of postoperative refractive error on visual acuity and patient satisfaction after implantation of the Array multifocal intraocular lens. J Cataract Refract Surg 2005;31(10):1960-5.

[9] Leyland M, Pringle E. Multifocal versus monofocal intraocular lenses after cataract extraction. Cochrane Database Syst Rev 2006;(4):CD003169.

[10] Pineda-Fernández A, Jaramillo J, Celis V, et al. Refractive outcomes after bilateral multifocal intraocular lens implantation. J Cataract Refract Surg 2004;30(23):685-8.

[11] Knorz MC. Multifocal intraocular lenses: overview of their capabilities, limitations and clinical benefits (editorial). J Refract Surg 2008;24(3):215-7.

[12] Vingolo EM, Grenga P, Lacobelli L, et al. Visual acuity and contrast sensitivity: AcrySof ReSTOR apodized diffractive versus AcrySof SA60AT monofocal intraocular lenses. J Cataract Refract Surg 2007;33(7):1244-7.

[13] Javitt JC, Steinert RF. Cataract extraction with multifocal intraocular lens implantation; a multinational clinical trial evaluating clinical, functional and quality-of-life outcomes. Ophthalmology 2000;107(11):2040-8.

[14] Chandhrasri S, Knorz MC. Comparison of higher order aberrations and contrast sensitivity after LASIK, Verisyse phakic IOL and Array multifocal IOL. J Refract Surg 2006;22(3):231-6.

[15] Jacobi PC, Konen W. Effect of age and astigmatism on the AMO Array multifocal intraocular lens. J Cataract Refract Surg 1995;21(5):556-61.

[16] Zeng M, Liu Y, Liu X, et al. Aberration and contrast sensitivity comparison of aspherical and monofocal and multifocal intraocular lens eyes. Clin Exp Ophthalmol 2007;35(4):355-60.

[17] Montés-Micó R, España E, Bueno I, et al. Visual performance with multifocal intraocular lenses: mesopic contrast sensitivity under distance and near conditions. Ophthalmology 2004;111(1):85-96.

[18] Pieh S, Lackner B, Hanselmayer G, et al. Halo size under distance and near conditions in refractive multifocal intraocular lenses. $\mathrm{Br} \mathrm{J}$ Ophthalmol 2001;85(7):816-21. 